\title{
Angiogenic and Vasculogenic Factors in the Vitreous from Patients with Proliferative Diabetic Retinopathy
}

\author{
Ahmed M. Abu El-Asrar, ${ }^{1,2}$ Mohd Imtiaz Nawaz, ${ }^{1}$ Dustan Kangave, \\ Mohammed Mairaj Siddiquei, ${ }^{1}$ and Karel Geboes ${ }^{3}$ \\ ${ }^{1}$ Department of Ophthalmology, College of Medicine, King Saud University, Riyadh, Saudi Arabia \\ ${ }^{2}$ Department of Ophthalmology, King Abdulaziz University Hospital, Old Airport Road, P.O. Box 245, Riyadh 11411, Saudi Arabia \\ ${ }^{3}$ Laboratory of Histochemistry and Cytochemistry, University of Leuven, Belgium
}

Correspondence should be addressed to Ahmed M. Abu El-Asrar; abuasrar@ksu.edu.sa

Received 22 December 2012; Accepted 12 February 2013

Academic Editor: Ghulam Mohammad

Copyright (C) 2013 Ahmed M. Abu El-Asrar et al. This is an open access article distributed under the Creative Commons Attribution License, which permits unrestricted use, distribution, and reproduction in any medium, provided the original work is properly cited.

\begin{abstract}
This study was conducted to determine levels of angiogenic and endothelial progenitor cell mobilizing (vasculogenic) factors in vitreous fluid from proliferative diabetic retinopathy (PDR) patients and correlate their levels with clinical disease activity. Vascular endothelial growth factor (VEGF), soluble vascular endothelial growth factor receptor-2 (sVEGFR-2), stem cell factor (SCF), soluble c-kit (s-kit), endothelial nitric oxide synthase (eNOS), and prostaglandin $\mathrm{E}_{2}\left(\mathrm{PGE}_{2}\right)$ levels were measured by ELISA in vitreous samples from 34 PDR and 15 nondiabetic patients. eNOS was not detected. VEGF, sVEGFR-2, SCF, and s-kit levels were significantly higher in PDR with active neovascularization compared with quiescent PDR and nondiabetic patients $(P<0.001 ; 0.007 ; 0.001$; $<0.001$, resp.). In contrast, $\mathrm{PGE}_{2}$ levels were significantly higher in nondiabetic patients compared with PDR patients $(P<0.001)$. There were significant correlations between levels of sVEGFR-2 versus SCF $(r=0.950, P<0.001)$, sVEGFR-2 versus s-kit $(r=$ $0.941, P<0.001)$, and SCF versus s-kit $(r=0.970, P<0.001)$. Our findings suggest that upregulation of VEGF, sVEGFR-2, SCF, and s-kit supports the contributions of angiogenesis and vasculogenesis in pathogenesis of PDR.
\end{abstract}

\section{Introduction}

Angiogenesis, the process by which new vascular networks develop from preexisting vessels, is a hallmark feature of proliferative diabetic retinopathy (PDR). In addition, increasing evidence suggests that vasculogenesis, the de novo formation of blood vessels from circulating bone marrow-derived endothelial progenitor cells (EPCs), can contribute to neovascularization. Recent studies have shown that circulating bone marrow-derived EPCs home to the ischemic region, differentiate into mature endothelial cells in situ, and can contribute to the process of neovascularization $[1,2]$. In previous studies, we demonstrated that bone marrow-derived $\mathrm{CD}_{133^{+}}{ }^{\mathrm{EPC}}$ and $\mathrm{c}-\mathrm{kit}^{+}$cells contribute to the new vessel formation in PDR fibrovascular epiretinal membranes $[3,4]$.

Angiogenesis and vasculogenesis are dependent on several cytokines/chemokines and their associated tyrosine kinase receptors. A key player of both these processes is vascular endothelial growth factor (VEGF), also called vascular permeability factor [5, 6]. VEGF binds with high affinity and activates two tyrosine kinase receptors, VEGFR-1 (Flt-1) and VEGFR-2 (KDR in humans/Flk-1 in mice). These receptors regulate physiological as well as pathological angiogenesis. From the postnatal to adult stage, VEGFR-2 is expressed mostly on vascular endothelial cells [7]. VEGFR-2 is also expressed by bone marrow-derived circulating EPCs. EPCs are characterized by the expression of markers like CD133, CD34, and VEGFR-2 [1, 2]. VEGFR-2 has strong tyrosine kinase activity and is the major positive signal transducer for pathological angiogenesis including cancer and diabetic retinopathy as well as microvascular permeability [7]. Activation of VEGFR-2 stimulates endothelial cell proliferation, migration, and survival, as well as angiogenesis and microvascular permeability [7]. VEGFR-2 has a truncated soluble form (sVEGFR-2) that can be detected in mouse and human plasma. However, it is unknown whether the SVEGFR-2 is a product of ectodomain shedding from cell-surface VEGFR-2 or a product of alternative mRNA splice variation $[8,9]$. 
Stem cell factor (SCF) or kit ligand is a peptide growth factor that exists as a membrane-bound protein but may be cleaved by proteases such as matrix metalloproteinase9 (MMP-9), to produce the soluble form [10-12]. SCF is important for the survival, proliferation, and differentiation of hematopoietic stem cells. The receptor for SCF, the protooncogene c-kit is a tyrosine kinase that is expressed by bone marrow-derived endothelial stem/progenitor cells that can give rise to endothelial cells $[13,14]$. SCF ligand binding leads to phosphorylation and activation of the c-kit receptor and its downstream signaling proteins which have been implicated in cell proliferation, cell adhesion, cell survival, chemotaxis, and mobilization of EPCs required for neovascularization $[11,12,15]$. SCF/c-kit signaling has been implicated in the regulation of angiogenesis $[10,13,15-18]$. A soluble form of ckit (s-kit), consisting of only the extracellular ligand-binding domain, that can be generated by proteolytic cleavage from the surface of hematopoietic cells, mast cells, and endothelial cells or by alternative splicing has been identified [19].

Several studies reported that endothelial nitric oxide synthase (eNOS) is crucial for the recruitment of EPCs in the circulation from the bone marrow and for firm c-kit ${ }^{+}$ cell adhesion to the vascular endothelium. eNOS is also required for neovascularization in ischemic tissue [20-23]. Recently, it was reported that prostaglandin $\mathrm{E}_{2}\left(\mathrm{PGE}_{2}\right)$, one of the major products of cyclooxygenase, plays an essential role in EPCs homeostasis [24]. In addition, $\mathrm{PGE}_{2}$ directly stimulates angiogenesis, apart from VEGF signaling, and further induces VEGF expression in endothelial cells [25].

We hypothesized that the vitreous levels of these biomarkers directly reflects angiogenesis and vasculogenesis in PDR. To elucidate the role of angiogenic and EPC mobilizing factors in PDR progression, we measured the levels of VEGF, sVEGFR-2, SCF, s-kit, eNOS, and $\mathrm{PGE}_{2}$ in the vitreous fluid from patients with PDR and patients without diabetes and correlated their levels with clinical disease activity.

\section{Materials and Methods}

2.1. Vitreous Samples Collection and Preparation. Undiluted vitreous fluid samples $(0.3-0.6 \mathrm{~mL})$ were obtained from individual eyes of from 34 patients with PDR during pars plana vitrectomy. The indications for vitrectomy were traction retinal detachment and/or nonclearing vitreous hemorrhage. The severity of retinal neovascular activity was graded clinically at the time of vitrectomy using previously published criteria [26]. Neovascularization was considered active if there were visible perfused new vessels on the retina or optic disc present within tractional epiretinal membranes. Neovascularization was considered inactive (involuted) if only nonvascularized; white fibrotic epiretinal membranes were present. Active PDR was present in 21 patients, and inactive PDR was present in 13 patients. Traction retinal detachment was present in 23 patients and vitreous hemorrhage in 16 patients. Vitreous hemorrhage was present in 12 patients with active PDR and in 4 patients with inactive PDR. The diabetic patients were 24 males and 10 females, whose ages ranged from 27 to 75 years with a mean of $53.3 \pm 11.7$ years. The duration of diabetes ranged from 7 to 32 years with a mean of $16.4 \pm 5.6$ years. Twenty-two patients had insulindependent diabetes mellitus, and 12 patients had noninsulindependent diabetes mellitus. At presentation, the fasting blood glucose was uncontrolled in 22 patients and controlled in 12 patients. Twenty-four patients were receiving treatment for hypertension, 3 patients had diabetic nephropathy, and 3 patients had cardiovascular disease. The control group consisted of 15 patients who had undergone vitrectomy for the treatment of rhegmatogenous retinal detachment (RD) with no proliferative vitreoretinopathy. Controls were free from systemic disease and were 10 males and 5 females whose ages ranged from 26 to 78 years with a mean of $52.6 \pm$ 15.2 years. None of the control patients had vitreous hemorrhage (Table 1). Vitreous samples were collected undiluted by manual suction into a syringe through the aspiration line of vitrectomy, before opening the infusion line. The samples were centrifuged (5000 rpm for $10 \mathrm{~min}, 4^{\circ} \mathrm{C}$ ), and the supernatants were aliquoted and frozen at $-80^{\circ} \mathrm{C}$ until assay. The study was conducted according to the tenets of the Declaration of Helsinki, and informed consent was obtained from all patients. The study was approved by the Research Centre, College of Medicine, King Saud University.

2.2. Enzyme-Linked Immunosorbent Assay Kits. Enzymelinked immunosorbent assay (ELISA) kits for human VEGF (Quantikine Human Vascular Endothelial Growth Factor, Cat number: SVE00), human sVEGFR-2 (Quantikine Human Vascular Endothelial Growth Factor Receptor 2, Cat number: SVR200), human SCF (Quantikine Human Stem Cell Factor/c-kit ligand, Cat number: DCK00), human s-kit (Quantikine Human Stem Cell Factor soluble receptor, SCF sR, Cat number: DSCR00), and eNOS (Quantikine Human Endothelial Nitric Oxide Synthase, Cat number: DEN00) were purchased from R and D Systems, Minneapolis, MN. Whereas, PGE $_{2}$ (Quantikine Human Prostaglandin E2, Cat number: 514010) was purchased from Cayman Chemical Company, Ann Arbor, NI. The detection limit of each ELISA kit for VEGF, sVEGFR-2, SCF, s-kit, eNOS, and $\mathrm{PGE}_{2}$ is 9.0, $4.6,9.0,65,25$, and 15 picograms/ $\mathrm{mL}(\mathrm{pg} / \mathrm{mL})$, respectively. The ELISA plate readings were done using FLUOstar OmegaMiroplate reader from BMG Labtech, Offenburg, Germany.

2.3. Measurement of Human VEGF, sVEGFR-2, SCF, s-Kit, and eNOS. The quantifications of the level of VEGF, sVEGFR-2, SCF, s-kit, and eNOS in the vitreous fluid were determined using specific ELISA kits according to the manufacturer's instruction ( $\mathrm{R}$ and D Systems).

Vitreous samples were diluted 2-fold, 3-fold, and 2-fold for VEGF, sVEGFR-2 and SCF measurements, respectively. $100 \mu \mathrm{L}$ of diluted sample was added to each well of the ELISA plate for the analysis. For the measurement of s-kit and eNOS, vitreous was not diluted, and $100 \mu \mathrm{L}$ of undiluted sample was used in the ELISA assay. Optical density was read at $450 \mathrm{~nm}$ in microplate reader. Each assay was performed in duplicate. Using the 4-parameter fit logistic (4-PL) curve equation, the actual concentration for each sample was calculated. For the vitreous samples that have been diluted, the correction read from the standard curve obtained using 4-PL was multiplied 


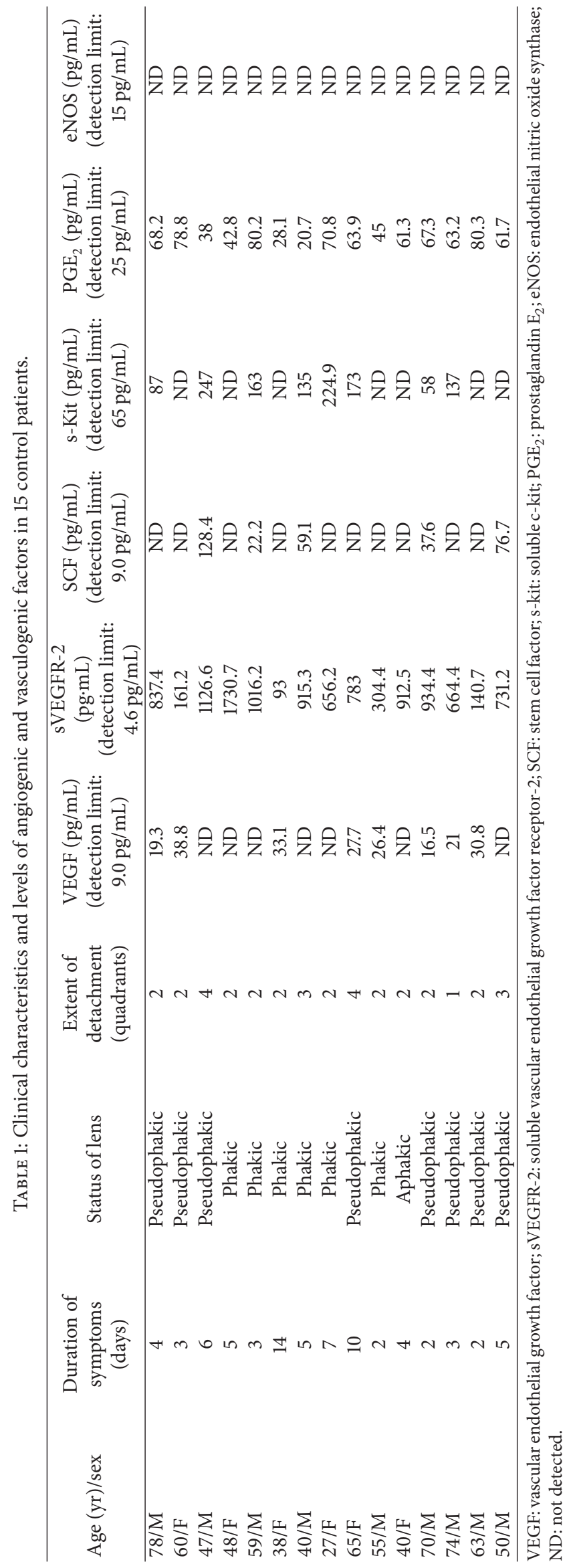


by the dilution factors to get the actual reading for each sample.

2.4. Measurement of Human Prostaglandin $E_{2}$. The quantification of the level of $\mathrm{PGE}_{2}$ in the vitreous fluid was determined using a specific ELISA kit according to the manufacturer's instruction (Cayman Chemical Company). $50 \mu \mathrm{L}$ of 2 -fold diluted vitreous fluid was added to each ELISA well followed by the addition of $\mathrm{PGE}_{2} \mathrm{AChE}$ tracer (acetylcholinesterase) and $\mathrm{PGE}_{2}$ monoclonal antibodies. The antibody- $\mathrm{PGE}_{2}$ complex binds to goat polyclonal anti-mouse IgG that has been previously attached to the well. The plate was washed after incubation for 18 hours at $4^{\circ} \mathrm{C}$ to remove any unbound reagents, and then Ellman's Reagent (which contains the substrate to AChE) is added to the well. The product of this enzymatic reaction gives yellow color, and the corresponding optical density was measured at $405 \mathrm{~nm}$ using microplate reader. The intensity of this color is proportional to the amount of $\mathrm{PGE}_{2}$ tracer bound to the well, which in turn is inversely proportional to the amount of free $\mathrm{PGE}_{2}$ present in the well. The $\% \mathrm{~B} / \mathrm{B} 0$ (\%Bound/Maximum Bound) is calculated which is ratio of the absorbance of a particular sample or standard well to that of the maximum binding (B0) well. Using the 4-parameter fit logistic (4-PL) curve equation, the actual concentration for each sample was calculated using standard curve that was plotted using $\% \mathrm{~B} / \mathrm{B} 0$ values versus concentration of a series of wells containing series of known amounts of $\mathrm{PGE}_{2}$. As the vitreous fluid has been 2 -fold diluted, the correction read from the standard curve obtained using 4-PL was multiplied by the dilution factors to get the actual reading for each sample.

2.5. Statistical Analysis. The Mann-Whitney test was used to compare means from two independent groups. Pearson correlation coefficients were computed to investigate correlations between variables. One-way ANOVA and post-ANOVA pairwise comparisons of means were conducted using the Kruskal-Wallis test. For three groups, the critical $Z$ value for post-ANOVA pairwise mean comparisons was $Z=2.39$ at a $5 \%$ level of significance. A $P$ value less than 0.05 indicated statistical significance. SPSS version 12.0 and program $3 S$ from the BMDP 2007 Statistical Package were used for the statistical analyses.

\section{Results}

3.1. Levels of Angiogenic and Vasculogenic Factors in Vitreous Samples. VEGF was detected in all vitreous samples from patients with PDR and in $8(53.0 \%)$ samples from nondiabetic control patients (Table 1). When all patients were considered, mean VEGF level in vitreous samples from PDR patients $(711.6 \pm 1271.3 \mathrm{pg} / \mathrm{mL})$ was significantly higher than that in nondiabetic control patients $(31.6 \pm 37.9 \mathrm{pg} / \mathrm{mL})(P<0.001$; Mann-Whitney test).

sVEGFR-2 was detected in all vitreous samples from patients with PDR and nondiabetic control patients (Table 1). The detected sVEGFR-2 levels in PDR patients $(1497.0 \pm 1590.5 \mathrm{pg} / \mathrm{mL})$ were significantly higher than that in nondiabetic control patients $(678.0 \pm 471.5 \mathrm{pg} / \mathrm{mL})(P=$ 0.002; Mann-Whitney test).

SCF was detected in all vitreous samples from patients with PDR and in 5 (33.0\%) samples from nondiabetic control patients (Table 1). SCF mean level in vitreous samples from PDR patients $(176.6 \pm 490.1 \mathrm{pg} / \mathrm{mL})$ was significantly higher than that in nondiabetic control patients $(21.6 \pm 38.5 \mathrm{pg} / \mathrm{mL})$ $(P<0.001$; Mann-Whitney test $)$.

s-kit was detected in all vitreous samples from patients with PDR and in 8 (53.0\%) samples from nondiabetic control patients (Table 1). s-kit mean level in vitreous samples from PDR patients $(493.8 \pm 1183.1 \mathrm{pg} / \mathrm{mL})$ was significantly higher than that in nondiabetic control patients $(87.5 \pm 91.5 \mathrm{pg} / \mathrm{mL})$ $(P<0.001$; Mann-Whitney test $)$.

$\mathrm{PGE}_{2}$ was detected in all vitreous samples from patients with PDR and nondiabetic control patients (Table 1). The detected $\mathrm{PGE}_{2}$ levels in PDR patients $(28.7 \pm 10.6 \mathrm{pg} / \mathrm{mL})$ were significantly lower than that in nondiabetic control patients $(58.0 \pm 18.8 \mathrm{pg} / \mathrm{mL})(P<0.001$; Mann-Whitney test $)$. eNOS was not detected in vitreous samples from patients with PDR and nondiabetic control patients.

3.2. Relationship between Angiogenic and Vasculogenic Factors and Activity of PDR. Comparison of mean levels of angiogenic and vasculogenic factors among active PDR patients, inactive PDR patients, and nondiabetic control patients was conducted using the Kruskal-Wallis test, and the results are shown in Table 2 . Mean levels differed significantly between the 3 groups for VEGF $(P<0.001)$, sVEGFR-2 $(P=0.007)$, SCF $(P=0.001)$, s-kit $(P<0.001)$, and $\mathrm{PGE}_{2}(P<0.001)$. Post-ANOVA pairwise comparisons of means indicated that mean VEGF level was significantly higher in patients with active PDR than in patients with inactive PDR $(Z=3.67)$ and nondiabetic control patients $(Z=5.25)$. For sVEGFR2 , mean level for patients with active PDR was significantly higher than that in nondiabetic control patients $(Z=3.11)$. For SCF, the mean levels for patients with active PDR and patients with inactive PDR were significantly higher than that in nondiabetic control patients ( $Z=3.42 ; Z=3.02$, resp.). For s-kit, the mean level for patients with active PDR was significantly higher than that in nondiabetic control patients $(Z=4.0)$. For $\mathrm{PGE}_{2}$, the mean levels for patients with active PDR and patients with inactive PDR were significantly lower than that in nondiabetic control patients $(Z=3.73 ; Z=2.73$, resp.).

3.3. Relationship between Angiogenic and Vasculogenic Factors and Vitreous Hemorrhage. When patients with PDR were divided into those with or without hemorrhage, the mean levels of angiogenic and vasculogenic factors differed significantly between PDR patients with hemorrhage, PDR patients without hemorrhage, and nondiabetic control patients for VEGF $(P<0.001)$, sVEGFR-2 $(P=0.003)$, SCF $(P=$ $0.001)$, s-kit $(P=0.001)$, and $\mathrm{PGE}_{2}(P<0.001)$ (Table 3$)$. Post-ANOVA pairwise comparisons of means highlighted that for VEGF, the mean levels for PDR patients with or without hemorrhage were significantly higher than those for nondiabetic control patients ( $Z=4.75 ; Z=2.52$, resp.), 
TABLE 2: Comparisons of mean angiogenic and vasculogenic factor levels in proliferative diabetic retinopathy (PDR) patients with or without active neovascularization.

\begin{tabular}{lccccc}
\hline Disease group & VEGF $(\mathrm{pg} / \mathrm{mL})$ & sVEGFR-2 $(\mathrm{pg} / \mathrm{mL})$ & SCF $(\mathrm{pg} / \mathrm{mL})$ & $\mathrm{s}-\mathrm{kit}(\mathrm{pg} / \mathrm{mL})$ & PGE $(\mathrm{pg} / \mathrm{mL})$ \\
\hline Active PDR & $1099.9 \pm 1535.6$ & $1692.5 \pm 1873.9$ & $233.7 \pm 626.8$ & $697.4 \pm 1528.1$ & $28.2 \pm 11.1$ \\
Inactive PDR & $150.7 \pm 237.7$ & $1050.1 \pm 403.2$ & $88.6 \pm 66.2$ & $205.3 \pm 106.4$ & $30.0 \pm 10.1$ \\
Controls & $31.6 \pm 37.9$ & $678.0 \pm 471.5$ & $21.6 \pm 38.5$ & $87.5 \pm 91.5$ & $58.0 \pm 18.8$ \\
ANOVA $P$ value & $<0.001^{*}$ & $0.007^{*}$ & $0.001^{*}$ & $<0.001^{*}$ & $<0.001^{*}$ \\
\hline
\end{tabular}

${ }^{*}$ Statistically significant at $5 \%$ level.

VEGF: vascular endothelial growth factor; sVEGFR-2: soluble vascular endothelial growth factor receptor-2; SCF: stem cell factor; s-kit: soluble c-kit; PGE ${ }_{2}$ : prostaglandin $\mathrm{E}_{2}$.

TABLE 3: Comparisons of mean angiogenic and vasculogenic factor levels in proliferative diabetic retinopathy (PDR) patients with or without hemorrhage.

\begin{tabular}{|c|c|c|c|c|c|}
\hline Disease group & VEGF (pg/mL) & sVEGFR-2 $(\mathrm{pg} / \mathrm{mL})$ & $\mathrm{SCF}(\mathrm{pg} / \mathrm{mL})$ & s-kit (pg/mL) & $\mathrm{PGF}_{2}(\mathrm{pg} / \mathrm{mL})$ \\
\hline PDR with hemorrhage & $994.1 \pm 1357.4$ & $1567.9 \pm 2118.8$ & $253.1 \pm 660.2$ & $682.7 \pm 1643.0$ & $24.6 \pm 9.3$ \\
\hline PDR without hemorrhage & $453.6 \pm 1156.7$ & $1404.7 \pm 425.8$ & $84.7 \pm 56.4$ & $291.4 \pm 149.3$ & $34.1 \pm 10.3$ \\
\hline Controls & $31.6 \pm 37.9$ & $678.0 \pm 471.5$ & $21.6 \pm 38.5$ & $87.5 \pm 91.5$ & $58.0 \pm 18.8$ \\
\hline ANOVA $P$ value & $<0.001^{*}$ & $0.003^{*}$ & $0.001^{*}$ & $0.001^{*}$ & $<0.001^{*}$ \\
\hline
\end{tabular}

${ }^{*}$ Statistically significant at $5 \%$ level.

VEGF: vascular endothelial growth factor; sVEGFR-2: soluble vascular endothelial growth factor receptor-2; SCF: stem cell factor; s-kit: soluble c-kit; PGE ${ }_{2}$ : prostaglandin $\mathrm{E}_{2}$.

and the mean level for PDR patients with hemorrhage was significantly higher than that for PDR patients without hemorrhage $(Z=2.40)$. For sVEGFR-2, the mean levels for PDR patients with or without hemorrhage were significantly higher than those for nondiabetic control patients $(Z=3.37$; $Z=2.45)$. For SCF, the mean levels for PDR patients with or without hemorrhage were significantly higher than those for nondiabetic control patients $(Z=3.27 ; Z=3.21$, resp.). For s-kit, the mean levels for PDR patients with or without hemorrhage were significantly higher than those for nondiabetic control patients ( $Z=3.5 ; Z=2.88$, resp.). For $\mathrm{PGE}_{2}$, the mean level was significantly lower for PDR patients with hemorrhage than that for nondiabetic control patients $(Z=4.23)$.

There were no statistically significant relationships between vitreous levels of angiogenic and vasculogenic factors and systemic disease variables (Table 4).

3.4. Correlations. When all patients with diabetes were considered, there were significant correlations between vitreous fluid levels of sVEGFR-2 versus SCF $(r=0.950, P<0.001)$, sVEGFR-2 versus s-kit $(r=0.941, P<0.001)$, and SCF versus s-kit $(r=0.970, P<0.001)$ (Table 5).

\section{Discussion}

The present study is to our knowledge the first to assess the levels of sVEGFR-2, SCF, and s-kit in the vitreous fluid from patients with PDR. Because activation of VEGFR-2 plays an important role in tumor angiogenesis, clinical interest in monitoring plasma sVEGFR-2 levels in cancer patients has focused on its potential use as a surrogate biomarker for disease progression as well as assessing efficacy/activity of antiangiogenic drugs particularly those that target VEGF or VEGFR-2 $[9,27]$. In vitro studies showed that VEGFR2 downregulation from the cell surface leads to reduced sVEGFR-2 levels in the conditioned media from endothelial cells, and that sVEGFR-2 is derived mainly from shedding from endothelial cell surface. These findings imply that expression levels of VEGFR-2 and its soluble form are linked [9]. Therefore, increased levels of sVEGFR-2 in the vitreous from patients with PDR, particularly in patients with active PDR, may reflect increased cellular VEGFR-2. A VEGF-dependent increase in the shedding of sVEGFR2 by endothelial cells was demonstrated [28, 29]. In the present study, we detected higher levels of VEGF in patients with active PDR compared with patients with inactive PDR and nondiabetic patients. Collectively, these findings are consistent with our previous immunohistochemical studies in which we demonstrated the presence of VEGFR-2 $2^{+} \mathrm{CD} 34^{+}$ cells and $\mathrm{VEGF}^{+}$cells in the vascular endothelium of blood vessels and in the stroma in PDR fibrovascular epiretinal membranes. Furthermore, the numbers of blood vessels and stromal cells expressing VEGFR-2 and VEGF in membranes from patients with active PDR were significantly higher than that in membranes from patients with quiescent PDR $[3,30]$.

In a previous immunohistochemical study, we showed that bone marrow-derived $\mathrm{c}^{-\mathrm{kit}^{+}}$cells coexpressing the chemokine stromal cell-derived factor-1 receptor CXCR4 and eNOS contribute to new vessel formation in PDR fibrovascular epiretinal membranes. In addition, SCF was expressed by vascular endothelial cells and stromal cells. Furthermore, the expression of SCF and c-kit in membranes from patients with active neovascularization was significantly higher than that in membranes from patients with quiescent PDR [4]. We have extended those observations by showing that both SCF and s-kit levels were significantly elevated in vitreous from patients with PDR and were further increased in patients with 
TABLE 4: Relationship between angiogenic and vasculogenic factors and systemic disease variables.

\begin{tabular}{|c|c|c|c|c|c|}
\hline Variable & VEGF $(\mathrm{pg} / \mathrm{mL})$ & sVEGFR-2 (pg/mL) & $\mathrm{SCF}(\mathrm{pg} / \mathrm{mL})$ & s-kit (pg/mL) & $\mathrm{PGE}_{2}(\mathrm{pg} / \mathrm{mL})$ \\
\hline \multicolumn{6}{|l|}{ Type of diabetes } \\
\hline Insulin-dependent & $1125.4 \pm 1819.4$ & $1594.0 \pm 1950.7$ & $209.9 \pm 614.4$ & $601.3 \pm 1502.7$ & $29.6 \pm 10.6$ \\
\hline Noninsulin-dependent & $472.9 \pm 507.9$ & $1338.2 \pm 569.3$ & $116.5 \pm 75.5$ & $320.3 \pm 182.6$ & $28.8 \pm 11.1$ \\
\hline$P$ value & 0.611 & 0.698 & 0.118 & 0.578 & 0.972 \\
\hline \multicolumn{6}{|l|}{ Fasting blood glucose } \\
\hline Controlled & $1296.1 \pm 1115.8$ & $2133.0 \pm 2601.7$ & $313.4 \pm 809.2$ & $867.0 \pm 2014.4$ & $31.0 \pm 11.0$ \\
\hline Uncontrolled & $912.9 \pm 1815.2$ & $1158.1 \pm 504.8$ & $906 \pm 74.2$ & $297.9 \pm 177.0$ & $28.4 \pm 10.5$ \\
\hline$P$ value & 0.081 & 0.375 & 0.846 & 0.649 & 0.733 \\
\hline \multicolumn{6}{|l|}{ Hypertension } \\
\hline Yes & $1117.3 \pm 1757.7$ & $1639.4 \pm 1873.0$ & $209.4 \pm 573.0$ & $548.0 \pm 1358.0$ & $29.4 \pm 10.6$ \\
\hline No & $672.6 \pm 1063.8$ & $1008.8 \pm 535.1$ & $59.7 \pm 28.0$ & $330.6 \pm 196.2$ & $29.2 \pm 12.5$ \\
\hline$P$-value & 0.374 & 0.409 & 0.422 & 0.716 & 0.804 \\
\hline
\end{tabular}

VEGF: vascular endothelial growth factor; sVEGFR-2: soluble vascular endothelial growth factor receptor-2; SCF: stem cell factor; s-kit: soluble c-kit; PGE 2 : prostaglandin $\mathrm{E}_{2}$.

TABle 5: Pearson correlation coefficients.

\begin{tabular}{ccccc}
\hline & PGE $_{2}$ & VEGF & sVEGFR-2 & SCF \\
\hline VEGF & & & & \\
$r=$ & 0.054 & & & \\
$P=$ & 0.849 & & & \\
sVEGFR-2 & & & & \\
$r=$ & -0.060 & -0.151 & & \\
$P=$ & 0.785 & 0.590 & & \\
SCF & & & & \\
$r=$ & -0.085 & -0.002 & 0.950 & 0.970 \\
$P=$ & 0.699 & 0.991 & $<0.001^{*}$ & \\
s-kit & & & & \\
$r=$ & 0.001 & -0.021 & 0.941 & $<0.011^{*}$ \\
$P=$ & 0.998 & 0.926 & $<0.001^{*}$ & \\
\hline
\end{tabular}

* Statistically significant at $5 \%$ level.

Where the row and column meet, is the correlation coefficient and the $P$ value for the two variables.

VEGF: vascular endothelial growth factor; sVEGFR-2: soluble vascular endothelial growth factor receptor-2; SCF: stem cell factor; s-kit: soluble ckit; $\mathrm{PGE}_{2}$ : prostaglandin $\mathrm{E}_{2}$.

active PDR. Taken together, these findings suggest a role for the SCF/c-kit signaling in the progression of PDR.

Several reports demonstrated that SCF/c-kit signaling axis has been implicated in the regulation of angiogenesis. $\mathrm{SCF} / \mathrm{c}-$ kit signaling promoted the survival, migration, differentiation, and capillary tube formation of endothelial cells $[16,17]$ and induced a potent angiogenic response in vivo [17]. In addition, SCF/c-kit signaling played an important role in ischemia-induced neovascularization $[10$, $13,15,18]$. SCF has also been implicated in the mobilization of bone marrow-derived endothelial progenitor cells required for neovascularization $[12,15]$. Interestingly, several studies showed that SCF/c-kit signaling upregulates the transcription factor hypoxia-inducible factor-1 $\alpha$ (HIF-1 $\alpha$ ). SCF-induced HIF- $1 \alpha$ was transcriptionally active and transcribed HIF- $1 \alpha$ target genes, such as VEGF [31, 32]. On the other hand, Han et al. [33] demonstrated that hypoxia upregulates SCF gene expression through HIF-1 $\alpha$. These findings suggest a reciprocal effect between SCF and HIF-1 $\alpha$, thus forming a positive feedback in several cell lines coexpressing SCF and c-kit. In a previous report we demonstrated the presence of HIF- $1 \alpha$ immunoreactivity in PDR epiretinal membranes [34]. Treatment of small cell lung cancer cell line with imatinib, a specific inhibitor of the protein tyrosine kinases c-kit, and plateletderived growth factor receptor resulted in inhibition of c-kitinduced HIF- $1 \alpha$ and VEGF expression [31]. Imatinib has been shown to have clinical activity as an anticancer agent [35]. These findings suggest that inhibition of SCF/c-kit signaling could have clinically relevant antiangiogenic effects in PDR.

Several studies demonstrated that circulating levels of skit correlate with the clinical course of tumors and that the concentration of s-kit may be a useful clinical biomarker of disease severity in patients with tumors $[36,37]$. The serum levels of s-kit increase when the population of cells that release c-kit is pathologically expanded such as in acute myelogenous leukemia and mastocytosis $[38,39]$. Because $s$-kit is thought to be generated by the proteolytic cleavage of the membrane-bound receptor [19], it is possible that the increased levels in the vitreous from patients with PDR in part reflect increased $\mathrm{c}-\mathrm{kit}^{+}$cell numbers in PDR fibrovascular epiretinal membranes [4]. In addition, Nakamura et al. [40] demonstrated that exogenous s-kit induces mobilization of hematopoietic stem cells from bone marrow into peripheral blood. This finding is consistent with the observations of other investigators who demonstrated that the levels of s-kit in the serum showed a positive correlation with the numbers of peripheral blood stem cells [41]. The present study showed positive correlations between vitreous levels of SCF, s-kit, and sVEGFR-2. Similarly, c-kit and VEGFR-2 amplifications were strongly associated in glioblastoma multiforme, suggesting coamplification [42]. On the other hand, Turner et al. [43] demonstrated that s-kit retains high-affinity SCF binding activity suggesting that s-kit may bind SCF and function as a receptor antagonist.

eNOS is required for neovascularization in ischemic tissue $[22,23]$. In a mice model of hind-limb ischemia, impaired 
neovascularization in mice lacking eNOS is related to a defect in progenitor cell mobilization [22]. eNOS is involved in migration of EPCs [21] and is crucial and specific factor for firm c-kit ${ }^{+}$cell adhesion in the vascular endothelium [20]. In cell culture models, eNOS plays an essential role in endothelial cell proliferation and is a central mediator of several endothelium growth factors, such as VEGF and $\mathrm{PGE}_{2}$ [44]. In a previous immunohistochemical study, we showed immunoreactivity for eNOS in vascular endothelial cells and stromal cells in PDR fibrovascular epiretinal membranes [4]. In the present study, however, eNOS levels were below the detection limit. This discrepancy might be explained by the primary localization of eNOS on the Golgi apparatus and plasma membrane caveolae in endothelial cells [45] and therefore might not release into the vitreous fluid. The crucial role of $\mathrm{PGE}_{2}$ in EPCs homeostasis following tissue ischemia has been demonstrated. In vivo blockade of $\mathrm{PGE}_{2}$ production by selective cyclooxygenase- 2 inhibition virtually abrogated ischemia-induced EPCs mobilization. In addition, EPCs are a rich source of $\mathrm{PGE}_{2}$, and $\mathrm{PGE}_{2}$ stimulates the number and function of EPCs [24]. Furthermore, $\mathrm{PGE}_{2}$ directly stimulates angiogenesis, and this stimulatory effect is not dependent on VEGF signaling. $\mathrm{PGE}_{2}$ stimulation of endothelial cells enhances VEGF expression. In turn, VEGF stimulates $\mathrm{PGE}_{2}$ expression in endothelial cells [25]. However, in the present study, $\mathrm{PGE}_{2}$ levels in PDR patients were significantly lower than that in nondiabetic patients. These findings are consistent with the observations of other investigators [46].

The vitreous fluid, collected from patients with PDR during pars plana vitrectomy, is an ideal material for anal$y$ sis of local, intraocular concentrations of selected proteins which take part of this pathology. However, when measuring these factors in the vitreous, some considerations should be kept in mind. Vitreous hemorrhage, associated with active neovascularization or traction on the retina induced by involuted fibrovascular proliferation during posterior vitreous detachment, can provide an influx of serum proteins into vitreous fluid. In a previous study, we demonstrated that there was no correlation between hemoglobin levels, as a measure of the amount of erupted blood, and total protein levels in vitreous fluid from patients with PDR [47]. In addition, we showed that chemokine levels in vitreous samples were significantly higher than that in serum samples and that there was no correlation between vitreous fluid and serum chemokine levels in patients with PDR [48]. Our previous immunohistochemical studies demonstrated the expression of c-kit, SCF, VEGF, and VEGFR-2 by vascular endothelial cells and stromal cells in PDR fibrovascular epiretinal membranes $[3,4,30,34]$. In our laboratory, we also recently demonstrated upregulated expression of VEGF, VEGFR-2, and SCF in the retinas from diabetic mice (Mohammed et al., unpublished data). In addition, our subgroup analysis demonstrated that the levels of VEGF, sVEGFR-2, SCF, and s-kit were also increased in vitreous fluid from PDR patients without hemorrhage. These findings suggest that local cellular production is the relevant source of these factors within the ocular microenvironment and that systemic inflow mechanism is rather improbable.
In conclusion, our findings suggest that the upregulation of VEGF, sVEGFR-2, SCF, and s-kit in the vitreous fluid from patients with PDR reflects angiogenesis and vasculogenesis in PDR. These results have implications for understanding the pathogenetic mechanisms that underlie the neovascularization that develops as a complication of this disorder.

\section{Conflict of Interests}

The authors declare that they have no conflict of interests.

\section{Acknowledgments}

The authors thank Ms. Connie B. Unisa-Marfil for secretarial work. This work was supported by Dr. Nasser al-Rasheed Chair in Ophthalmology (Abu El-Asrar AM).

\section{References}

[1] B. Dome, J. Dobos, J. Tovari et al., "Circulating bone marrowderived endothelial progenitor cells: characterization, mobilization, and therapeutic considerations in malignant disease," Cytometry A, vol. 73, no. 3, pp. 186-193, 2008.

[2] T. Asahara, T. Murohara, A. Sullivan et al., "Isolation of putative progenitor endothelial cells for angiogenesis," Science, vol. 275, no. 5302, pp. 964-967, 1997.

[3] A. M. Abu El-Asrar, S. Struyf, H. Verbeke, J. Van Damme, and K. Geboes, "Circulating bone-marrow-derived endothelial precursor cells contribute to neovascularization in diabetic epiretinal membranes," Acta Ophthalmologica, vol. 89, no. 3, pp. 222-228, 2011.

[4] A. M. Abu El-Asrar, S. Struyf, G. Opdenakker, J. van Damme, and K. Geboes, "Expression of stem cell factor/c-kit signaling pathway components in diabetic fibrovascular epiretinal membranes," Molecular Vision, vol. 16, pp. 1098-1107, 2010.

[5] C. Kalka, H. Masuda, T. Takahashi et al., "Vascular endothelial growth factor165 gene transfer augments circulating endothelial progenitor cells in human subjects," Circulation Research, vol. 86, no. 12, pp. 1198-1202, 2000.

[6] B. Li, E. E. Sharpe, A. B. Maupin et al., "VEGF and PlGF promote adult vasculogenesis by enhancing EPC recruitment and vessel formation at the site of tumor neovascularization," FASEB Journal, vol. 20, no. 9, pp. E664-E676, 2006.

[7] M. Shibuya, "Differential roles of vascular endothelial growth factor receptor-1 and receptor-2 in angiogenesis," Journal of Biochemistry and Molecular Biology, vol. 39, no. 5, pp. 469-478, 2006.

[8] J. M. L. Ebos, G. Bocci, S. Man et al., "A naturally occurring soluble form of vascular endothelial growth factor receptor 2 detected in mouse and human plasma," Molecular Cancer Research, vol. 2, no. 6, pp. 315-326, 2004.

[9] J. M. L. Ebos, C. R. Lee, E. Bogdanovic et al., "Vascular endothelial growth factor-mediated decrease in plasma soluble vascular endothelial growth factor receptor-2 levels as a surrogate biomarker for tumor growth," Cancer Research, vol. 68, no. 2, pp. 521-529, 2008.

[10] S. S. Fazel, L. Chen, D. Angoulvant et al., "Activation of ckit is necessary for mobilization of reparative bone marrow progenitor cells in response to cardiac injury," FASEB Journal, vol. 22, no. 3, pp. 930-940, 2008. 
[11] P. H. Huang, Y. H. Chen, C. H. Wang et al., "Matrix metalloproteinase-9 is essential for ischemia-induced neovascularization by modulating bone marrow-derived endothelial progenitor Cells," Arteriosclerosis, Thrombosis, and Vascular Biology, vol. 29, no. 8, pp. 1179-1184, 2009.

[12] B. Heissig, Z. Werb, S. Rafii, and K. Hattori, "Role of c-kit/Kit ligand signaling in regulating vasculogenesis," Thrombosis and Haemostasis, vol. 90, no. 4, pp. 570-576, 2003.

[13] T. S. Li, K. Hamano, M. Nishida et al., "CD117+ stem cells play a key role in therapeutic angiogenesis induced by bone marrow cell implantation," American Journal of Physiology, vol. 285, no. 3, pp. H931-H937, 2003.

[14] Y. Miyamoto, T. Suyama, T. Yashita, H. Akimaru, and H. Kurata, "Bone marrow subpopulations contain distinct types of endothelial progenitor cells and angiogenic cytokine-producing cells," Journal of Molecular and Cellular Cardiology, vol. 43, no. 5, pp. 627-635, 2007.

[15] P. Dentelli, A. Rosso, A. Balsamo et al., "C-KIT, by interacting with the membrane-bound ligand, recruits endothelial progenitor cells to inflamed endothelium," Blood, vol. 109, no. 10, pp. 4264-4271, 2007.

[16] J. Matsui, T. Wakabayashi, M. Asada, K. Yoshimatsu, and M. Okada, "Stem cell factor/c-kit signaling promotes the survival, migration, and capillary tube formation of human umbilical vein endothelial cells," Journal of Biological Chemistry, vol. 279, no. 18, pp. 18600-18607, 2004.

[17] L. Sun, A. M. Hui, Q. Su et al., "Neuronal and glioma-derived stem cell factor induces angiogenesis within the brain," Cancer Cell, vol. 9, no. 4, pp. 287-300, 2006.

[18] D. J. Kelly, Y. Zhang, R. M. Gow, S. Itescu, and R. E. Gilbert, "Cells expressing the stem cell factor receptor, c-kit, contribute to neoangiogenesis in diabetes," Diabetes and Vascular Disease Research, vol. 2, no. 2, pp. 76-80, 2005.

[19] A. M. Turner, L. G. Bennett, N. L. Lin et al., "Identification and characterization of a soluble c-kit receptor produced by human hematopoietic cell lines," Blood, vol. 85, no. 8, pp. 2052-2058, 1995.

[20] A. Kaminski, N. Ma, P. Donndorf et al., "Endothelial NOS is required for SDF-1 $\alpha /$ CXCR4-mediated peripheral endothelial adhesion of c-kit+ bone marrow stem cells," Laboratory Investigation, vol. 88, no. 1, pp. 58-69, 2008.

[21] H. Zheng, G. Fu, T. Dai, and H. Huang, "Migration of endothelial progenitor cells mediated by stromal cell-derived factor1 $\alpha /$ CXCR4 via PI3K/Akt/eNOS signal transduction pathway," Journal of Cardiovascular Pharmacology, vol. 50, no. 3, pp. 274280, 2007.

[22] A. Aicher, C. Heeschen, C. Mildner-Rihm et al., "Essential role of endothelial nitric oxide synthase for mobilization of stem and progenitor cells," Nature Medicine, vol. 9, no. 11, pp. 1370-1376, 2003.

[23] K.-I. Hiasa, M. Ishibashi, K. Ohtani et al., "Gene transfer of stromal cell-derived factor- $1 \alpha$ enhances ischemic vasculogenesis and angiogenesis via vascular endothelial growth factor/endothelial nitric oxide synthase-related pathway: nextgeneration chemokine therapy for therapeutic neovascularization," Circulation, vol. 109, no. 20, pp. 2454-2461, 2004.

[24] T. Herrler, S. F. Leicht, S. Huber et al., "Prostaglandin e positively modulates endothelial progenitor cell homeostasis: an advanced treatment modality for autologous cell therapy," Journal of Vascular Research, vol. 46, no. 4, pp. 333-346, 2009.

[25] K. Tamura, T. Sakurai, and H. Kogo, "Relationship between prostaglandin $\mathrm{E}_{2}$ and vascular endothelial growth factor
(VEGF) in angiogenesis in human vascular endothelial cells," Vascular Pharmacology, vol. 44, no. 6, pp. 411-416, 2006.

[26] L. P. Aiello, R. L. Avery, P. G. Arrigg et al., "Vascular endothelial growth factor in ocular fluid of patients with diabetic retinopathy and other retinal disorders," New England Journal of Medicine, vol. 331, no. 22, pp. 1480-1487, 1994.

[27] E. Jantus-Lewintre, E. Sanmartīn, R. Sirera et al., "Combined VEGF-A and VEGFR-2 concentrations in plasma: diagnostic and prognostic implications in patients with advanced NSCLC," Lung Cancer, vol. 74, no. 2, pp. 326-331, 2011.

[28] S. Swendeman, K. Mendelson, G. Weskamp et al., "VEGFa stimulates ADAM17-dependent shedding of VEGFR2 and crosstalk between vegfr2 and ERK signaling," Circulation Research, vol. 103, no. 9, pp. 916-918, 2008.

[29] A. Stachon, A. Aweimer, T. Stachon et al., "Secretion of soluble VEGF receptor 2 by microvascular endothelial cells derived by human benign prostatic hyperplasia," Growth Factors, vol. 27, no. 2, pp. 71-78, 2009.

[30] A. M. Abu El-Asrar, L. Missotten, and K. Geboes, "Expression of cyclo-oxygenase-2 and downstream enzymes in diabetic fibrovascular epiretinal membranes," British Journal of Ophthalmology, vol. 92, no. 11, pp. 1534-1539, 2008.

[31] J. Litz and G. W. Krystal, "Imatinib inhibits c-Kit-induced hypoxia-inducible factor- $1 \alpha$ activity and vascular endothelial growth factor expression in small cell lung cancer cells," Molecular Cancer Therapeutics, vol. 5, no. 6, pp. 1415-1422, 2006.

[32] M. Pedersen, T. Löfstedt, J. Sun, L. Holmquist-Mengelbier, S. Påhlman, and L. Rönnstrand, "Stem cell factor induces HIF-1 $\alpha$ at normoxia in hematopoietic cells," Biochemical and Biophysical Research Communications, vol. 377, no. 1, pp. 98-103, 2008.

[33] Z.-B. Han, H. Ren, H. Zhao et al., "Hypoxia-inducible factor (HIF)-1 $\alpha$ directly enhances the transcriptional activity of stem cell factor (SCF) in response to hypoxia and epidermal growth factor (EGF)," Carcinogenesis, vol. 29, no. 10, pp. 1853-1861, 2008.

[34] A. M. A. Abd El-Asrar, L. Missotten, and K. Geboes, "Expression of hypoxia-inducible factor- $1 \alpha$ and the protein products of its target genes in diabetic fibrovascular epiretinal membranes," British Journal of Ophthalmology, vol. 91, no. 6, pp. 822-826, 2007.

[35] G. D. Demetri, "Differential properties of current tyrosine kinase inhibitors in gastrointestinal stromal tumors," Seminars in Oncology, vol. 38, supplement 1, pp. S10-S19, 2011.

[36] H. Takeshima and J. I. Kuratsu, "A review of soluble c-kit (s-kit) as a novel tumor marker and possible molecular target for the treatment of CNS germinoma," Surgical Neurology, vol. 60, no. 4, pp. 321-324, 2003.

[37] S. E. DePrimo, X. Huang, M. E. Blackstein et al., "Circulating levels of soluble KIT serve as a biomarker for clinical outcome in gastrointestinal stromal tumor patients receiving sunitinib following imatinib failure," Clinical Cancer Research, vol. 15, no. 18, pp. 5869-5877, 2009.

[38] M. Kawakita, Y. Yonemura, H. Miyake et al., "Soluble c-kit molecule in serum from healthy individuals and patients with haemopoietic disorders," British Journal of Haematology, vol. 91, no. 1, pp. 23-29, 1995.

[39] C. Akin, L. B. Schwartz, T. Kitoh et al., "Soluble stem cell factor receptor (CD 117) and IL-2 receptor alpha chain (CD25) levels in the plasma of patients with mastocytosis: relationships to disease severity and bone marrow pathology," Blood, vol. 96, no. 4, pp. 1267-1273, 2000. 
[40] Y. Nakamura, F. Tajima, K. Ishiga et al., "Soluble c-kit receptor mobilizes hematopoietic stem cells to peripheral blood in mice," Experimental Hematology, vol. 32, no. 4, pp. 390-396, 2004.

[41] K. Ishiga, "Serum-soluble c-kit levels during mobilization of peripheral blood stem cells correlate with stem cell yield," International Journal of Hematology, vol. 72, no. 2, pp. 186-193, 2000.

[42] H. Joensuu, M. Puputti, H. Sihto, O. Tynninen, and N. N. Nupponen, "Amplification of genes encoding KIT, PDGFR $\alpha$ and VEGFR2 receptor tyrosine kinases is frequent in glioblastoma multiforme," Journal of Pathology, vol. 207, no. 2, pp. 224-231, 2005.

[43] A. M. Turner, L. G. Bennett, N. L. Lin et al., "Identification and characterization of a soluble c-kit receptor produced by human hematopoietic cell lines," Blood, vol. 85, no. 8, pp. 2052-2058, 1995.

[44] L. Ying and L. J. Hofseth, "An emerging role for endothelial nitric oxide synthase in chronic inflammation and cancer," Cancer Research, vol. 67, no. 4, pp. 1407-1410, 2007.

[45] R. D. Minshall, W. C. Sessa, R. V. Stan, R. G. W. Anderson, and A. B. Malik, "Caveolin regulation of endothelial function," American Journal of Physiology, vol. 285, no. 6, pp. L1179-L1183, 2003.

[46] S. Douros, B. A. Phillips, A. Nadel, and S. A. Obstbaum, "Human vitreal prostaglandin levels and proliferative diabetic retinopathy," Documenta Ophthalmologica, vol. 103, no. 1, pp. 27-34, 2001.

[47] F. J. Descamps, E. Martens, D. Kangave et al., "The activated form of gelatinase B/matrix metalloproteinase- 9 is associated with diabetic vitreous hemorrhage," Experimental Eye Research, vol. 83, no. 2, pp. 401-407, 2006.

[48] A. M. Abu El-Asrar, S. Struyf, D. Kangave, K. Geboes, and J. Van Damme, "Chemokines in proliferative diabetic retinopathy and proliferative vitreoretinopathy," European Cytokine Network, vol. 17, no. 3, pp. 155-165, 2006. 


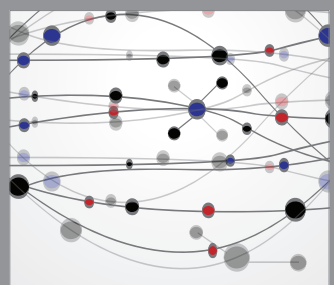

The Scientific World Journal
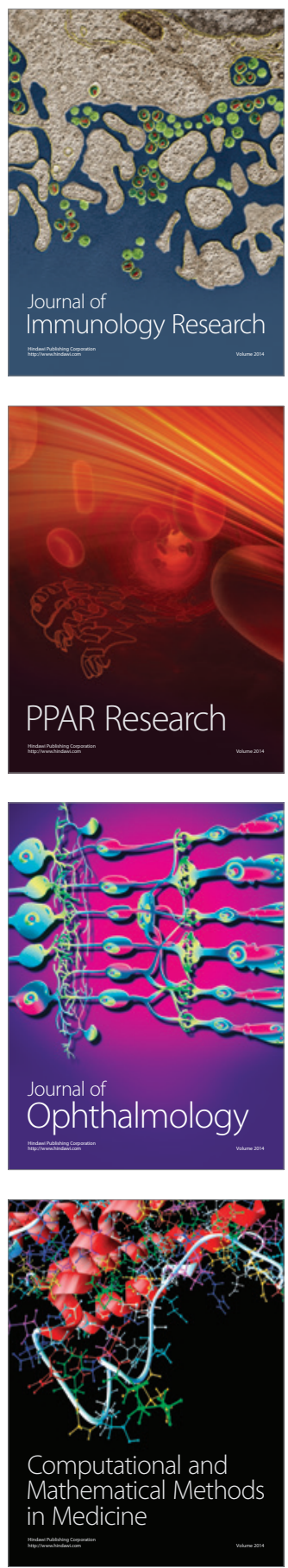

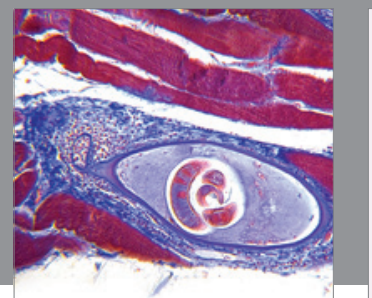

Gastroenterology

Research and Practice
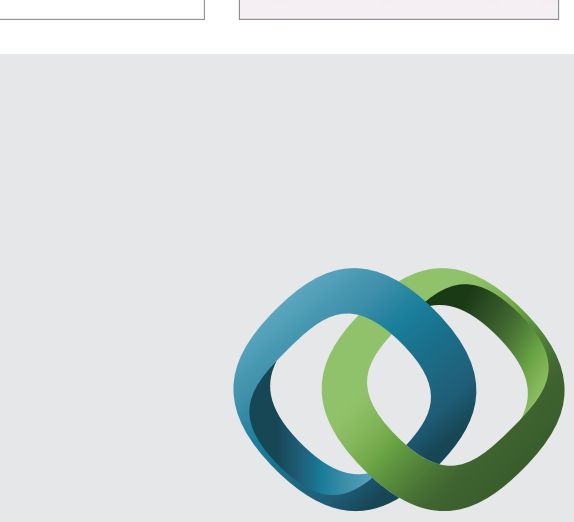

\section{Hindawi}

Submit your manuscripts at

http://www.hindawi.com
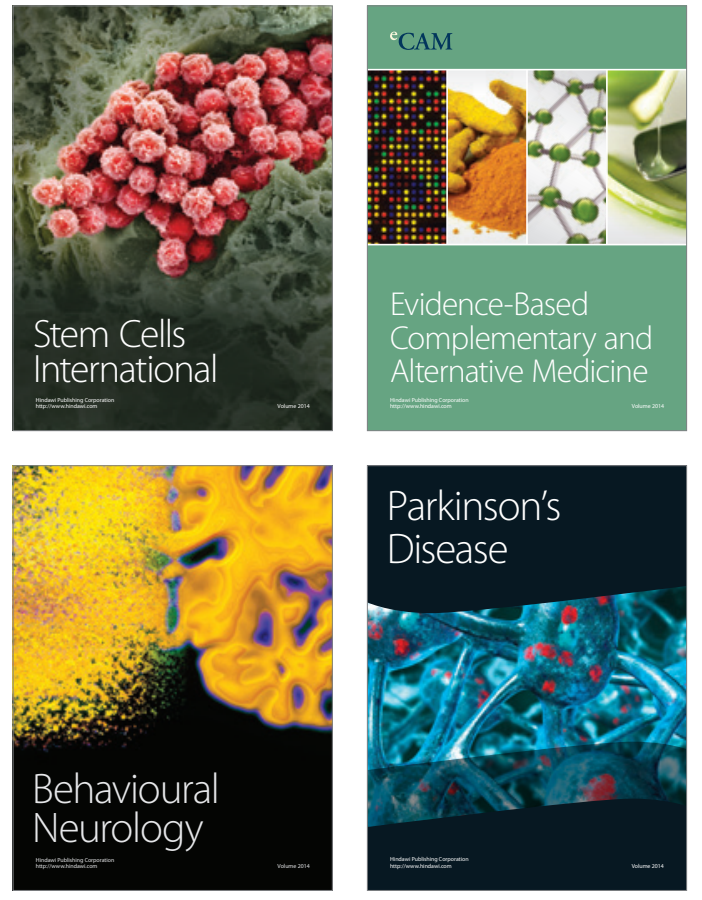
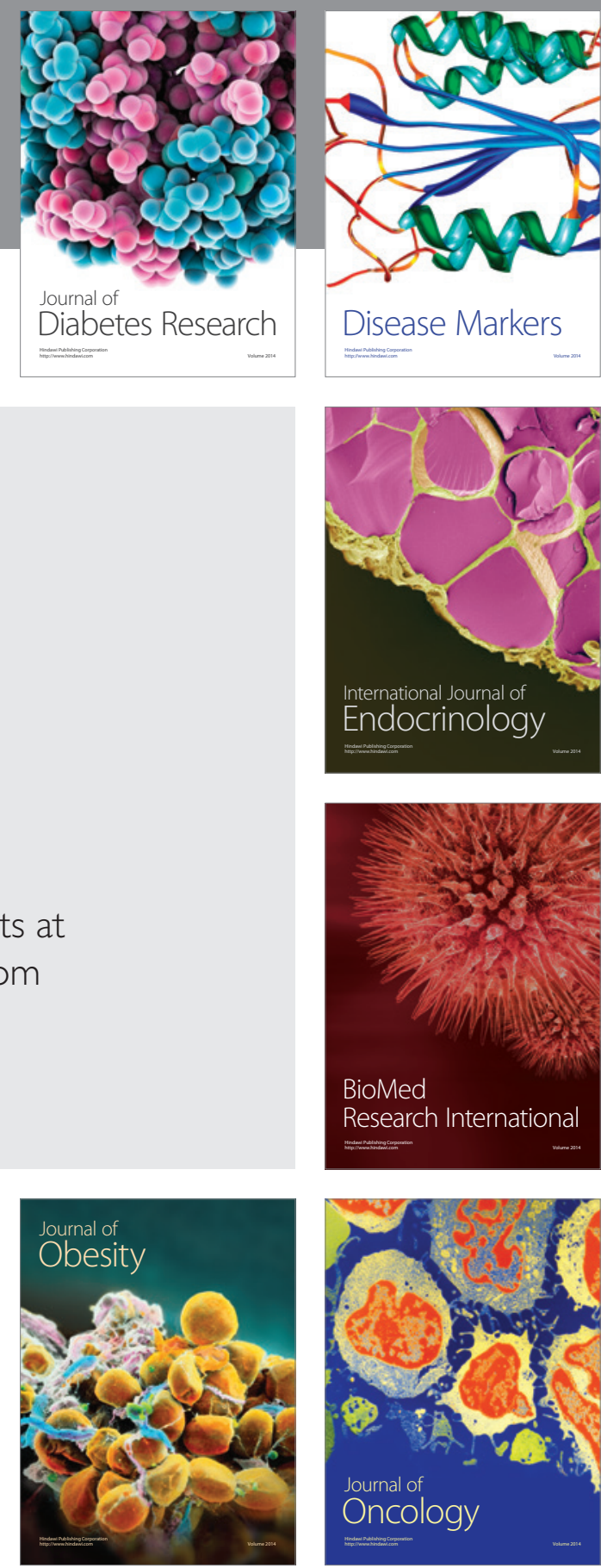

Disease Markers
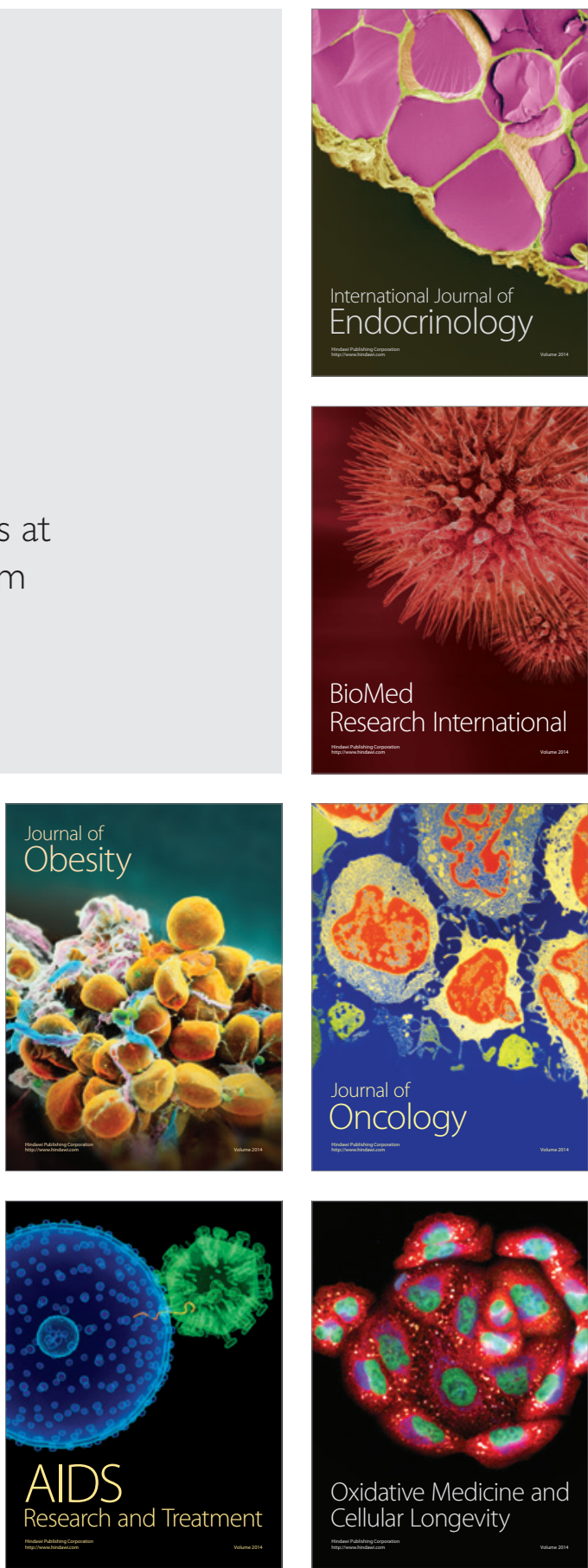